\title{
Evaluation of cytotoxic effect of the combination of a pyridinyl carboxamide derivative and oxaliplatin on NCI-H1299 human non-small cell lung carcinoma cells
}

\author{
Sarah Fernandes Teixeira ${ }^{\mathrm{a}}$, Ricardo Alexandre de Azevedo ${ }^{\mathrm{b}}$, Arthur Carvalho Silva $^{\mathrm{c}}$, \\ Rodolpho Campos Braga ${ }^{c}$, Salomão Dória Jorge ${ }^{\mathrm{b}}$, José Alexandre Marzagão Barbuto ${ }^{\mathrm{b}}$, \\ Carolina Horta Andradec, , Dr.Adilson Kleber Ferreira ${ }^{\mathrm{b}, *}$ \\ a Department of Pharmacology, Institute of Biomedical Science, University of São Paulo, Prof. Lineu Prestes Avenue, 1730 Sao Paulo - SP, Brazil \\ ${ }^{\mathrm{b}}$ Laboratory of Tumor Immunology, Department of Immunology, Institute of Biomedical Science, University of São Paulo, Prof. Lineu Prestes Avenue, 1730 Sao \\ Paulo - SP, Brazil \\ ${ }^{\mathrm{c}}$ LabMol - Laboratory for Molecular Modeling and Drug Design, Faculty of Pharmacy, Federal University of Goias, 240 Street, 74605-170, Goiania - GO, \\ Brazil
}

\section{A R T I C L E I N F O}

\section{Article history:}

Received 4 July 2016

Received in revised form 24 September 2016 Accepted 9 October 2016

\section{Keywords:}

Lung cancer

Pyridinyl carboxamide derivative

Apoptosis

Synergism

Oxaliplatin

\begin{abstract}
A B S T R A C T
Even with all improvements in both diagnostic and therapeutic techniques, lung cancer remains as the most lethal and prevalent cancer in the world. Therefore, new therapeutic drugs and new strategies of drug combination are necessary to provide treatments that are more efficient. Currently, standard therapy regimen for lung cancer includes platinum drugs, such as cisplatin, oxaliplatin, and carboplatin. Besides of the better toxicity profile of oxaliplatin when compared with cisplatin, peripheral neuropathy remains as a limitation of oxaliplatin dose. This study presents LabMol-12, a new pyridinyl carboxamide derivative with antileishmanial and antichagasic activity, as a new hit for lung cancer treatment, which induces apoptosis dependent of caspases in NCI-H1299 lung cancer cells both in monolayer and 3D culture. Moreover, LabMol-12 allows a reduction of oxaliplatin dose when they are combined, thereby, it is a relevant strategy for reducing the side effects of oxaliplatin with the same response. Molecular modeling studies corroborated the biological findings and suggested that the combined therapy can provide a better therapeutically profile effects against NSCLC. All these findings support the fact that the combination of oxaliplatin and LabMol-12 is a promising drug combination for lung cancer.
\end{abstract}

(c) 2016 Elsevier Masson SAS. All rights reserved.

\section{Introduction}

Lung cancer is the most deadly and the second most incident cancer both in men and women in the United States [1,2]. Nonsmall cell lung cancer (NSCLC), which mainly includes adenocarcinoma, squamous cell carcinoma and large cell carcinoma,

\footnotetext{
Abbreviations: NSCLC, Non-small cell lung cancer; VS, virtual screening; EGFR, epidermal growth factor receptor; ALK, anaplastic lymphoma kinase; FDA, Food and Drug Administration; PBS, phosphate buffered saline; DMSO, dimethyl sulfoxide; MTT, 3-[4,5-dimethylthiazol-2-yl]-2,5-diphenyltetrazolium bromide; PI, Propidium Iodide; FBS, fetal bovine serum; CI, combination index; MEP, molecular electrostatic potential maps; HOMO, highest occupied molecular orbital; LUMO, lowest unoccupied molecular orbital; ClogP, calculated octanol/water partition coefficient.

* Corresponding author at: Prof. Lineu Prestes Avenue, 1730, Laboratory of Tumor Immunology, Department of Immunology, Institute of Biomedical Science, University of São Paulo, São Paulo - SP, Brazil.

E-mail address: ferreira-kleber@usp.br (A.K. Ferreira).
}

accounts for nearly $84 \%$ of lung cancers cases. Unfortunately, even with improvements in both diagnostic and therapeutic techniques, the overall 5-year survival rate remains poor [2]. Therefore, new therapeutic options and new strategies, as well as drug combination are necessary to provide treatments that are more efficient.

Currently, standard therapy regimen for advanced NSCLC includes a platinum drug associated with third-generation agents [3]. In this regard, oxaliplatin is a platinum analog that inhibits DNA replication and is effective against NSCLC [4-8]. Furthermore, oxaliplatin has fewer toxicity effects than its prototype, cisplatin [9]. However, oxaliplatin has a dose limitation to clinical use by peripheral neuropathy induction, and new strategies must be developed to overcome this common side effect [10].

Besides toxicity issue of current NSCLC therapy, distinct biology and clinical outcomes in this disease are another substantial hindrance [11]. Therefore, several targeting therapies approved are helpful is some cases to overcome this biological disparity, such as 
the use of epidermal growth factor receptor (EGFR) or anaplastic lymphoma kinase (ALK) tyrosine kinase inhibitors, but there are no Food and Drug Administration (FDA) approved drugs that target the most common driver oncogenic driver, mutant KRAS [12]. Mutations in ras gene are highly prevalent in human cancers, especially in lung cancer, and associated with a poor prognosis. Thus, Ras pathway is an attractive target for antitumor drug development $[13,14]$. Ras proteins are farnesylated, a critical step, since c-terminal farnesylation enables Ras membrane association and transformation, therefore, the inhibition of this step prevents chronically activated Ras proteins in cancer [15].

Several research groups discovered a correlation between some antitumor drugs with antichagasic activity due to CYP51 inhibition [16]. Furthermore, some CYP51 inhibitors also inhibit human protein farnesyltransferase (PFT), thereby they block Ras transduction pathway signal and stop cell growth [17-19]. In this context, we have been interested in investigating anti-tumor activity of LabMol-12, a new pyridinyl carboxamide derivative identified in a virtual screening (VS) campaign in LabMol as a new leishmanicidal hit [20]. This compound was previously described as an inhibitor of sterol $14 \alpha$-demethylase (CYP51) in Trypanosoma cruzi [21], referenced previously as LP-10 [22,23]. CYP51 enzyme is involved in ergosterol biosynthesis and catalyzes a three-step reaction resulting in the oxidative removal of $14 \alpha$-methyl group of lanosterol, a precursor of ergosterol [24]. Moreover, it was shown that LabMol-12 has antichagasic activity both in vitro and in vivo models [21,23]. Driven by the information that tipifarnib, an anticancer drug candidate that is an inhibitor of human protein farnesyltransferase (PFT), was also described as an inhibitor of CYP51 of T. cruzi [25] and also based on the similarity between this tipifarnib and LabMol-12, we decided to test if LabMol-12 has antitumor activity.

Moreover, motivated by the need of reduction of oxaliplatin's dose with improvement of its activity, we investigated the effects related to the association of oxaliplatin and LabMol-12 in NCIH1299, a NSCLC cell line, as well as performed molecular modeling studies to investigate whether the combined therapy can provide a better therapeutically profile effects against NSCLC.

\section{Material and methods}

\subsection{Drugs and chemicals}

Oxaliplatin was provided by Eurofarma (São Paulo, SP, Brazil) and diluted in phosphate buffered saline (PBS). LabMol-12 [N-(3(1H-indol-3-yl)-1-oxo-1-(pyridin-4-ylamino)propan-2-yl)-4methylcyclohexane-1-carboxamide] was purchased from ChemDiv (C155-0123) (San Diego, CA, USA) and diluted in dimethyl sulfoxide (DMSO) before the experiments. Annexin V-FITC apoptosis detection kit was obtained from BD Biosciences (Franklin Lakes, NJ, USA). Whereas the 3-[4,5-dimethylthiazol-2-yl]-2,5diphenyltetrazolium bromide (MTT), RNase and Propidium Iodide (PI) and Tetramethylrhodamine ethyl ester (TMRE) were acquired from Sigma-Aldrich (MO, USA). Growth factor reduced Matrigel was purchased from BD Bioscience (Franklin Lakes, NJ, USA). The anti-caspase 3 and $\beta$ actin primary antibodies used (Cell Signaling, Technology, Beverly, MA, USA) at a 1:1000 dilution and secondary antibodies were purchased from Cell Signaling (Technology, Beverly, MA, USA).

\subsection{Cell culture}

Human lung carcinoma cell line NCI-H1299 was purchased from Rio de Janeiro Cell Bank (Duque de Caxias, RJ, Brazil). These cells were maintained in RPMI-1640 (Sigma-Aldrich, MO, USA) supplemented with $10 \%(\mathrm{v} / \mathrm{v})$ fetal bovine serum (FBS) (Gibco,
Karlsruhe, Germany) and $1 \%$ penicillin-streptomycin at $37^{\circ} \mathrm{C}$ under a humidified atmosphere of $5 \% \mathrm{CO}_{2}$.

\subsection{Cell viability assay}

Cells were seeded into 96-well plates with $1 \times 10^{4}$ cells/well in $0.1 \mathrm{~mL}$ of medium with $10 \%$ FBS and allowed to adhere for $2 \mathrm{~h}$. In other to evaluate well-known apoptosis phenomena, caspases activity, and DNA fragmentation, first, a pretreatment with $50 \mu \mathrm{M}$ of BAPTA, $100 \mu \mathrm{M}$ of Z-VAD or vehicle (control group) was performed for $2 \mathrm{~h}$. Then, varying the concentration of oxaliplatin $(10,5$ and $2.5 \mu \mathrm{M})$ alone or combined with $10 \mu \mathrm{M}$ of LabMol-12 were used to treat the cells for $24 \mathrm{~h}$. Afterward, MTT solution ( $5 \mathrm{mg} /$ $\mathrm{mL}$ in PBS) was added to each well, and the plate was incubated for an additional $3 \mathrm{~h}$ at the same conditions previously described. Subsequently, the plate was centrifuged, and formazan crystals formed by viable cells was dissolved in $100 \mu \mathrm{L}$ DMSO. The absorbance was measured on a microplate reader at $538 \mathrm{~nm}$.

\subsection{Growth inhibition assay}

Cells were seeded into 96-well plates at the density of $1 \times 10^{4}$ cells/well in $0.1 \mathrm{~mL}$ of medium allowed to adhere for $2 \mathrm{~h}$. Next, cells were treated with oxaliplatin at concentrations of 10,5 and $2.5 \mu \mathrm{M}$ alone or combined with $10 \mu \mathrm{M}$ of LabMol-12 diluted in medium with varying concentration (1, 10 or $20 \%$ ) of FBS to evaluate treatments effects in cell with different proliferations levels. After three days of treatment, cell growth was determinate by cell count in Neubauer chamber. Cell growth inhibition was expressed as 50\% of growth inhibition $\left(\mathrm{GI}_{50}\right)$ compared to counted cells in the control group with $1 \%$ of FBS.

\subsection{Drug combination study}

The combination index (CI) was calculated by the Chou-Talalay equation using CompuSyn software v. 1.0 [26], which takes into account both potency $\left(\mathrm{IC}_{50}\right)$ and the shape of the dose-effect curve of each drug. The general equation for the classic isobologram is given by: $\mathrm{CI}=(\mathrm{D})_{1} /(\mathrm{Dx})_{1}+(\mathrm{D})_{2} /(\mathrm{Dx})_{2}+\left[(\mathrm{Dx})_{1} /(\mathrm{Dx})_{2}\right] /\left[(\mathrm{D})_{1}+(\mathrm{D})_{2}\right]$, where $(\mathrm{Dx})_{1}$ and $(\mathrm{Dx})_{2}$ are the doses of $\mathrm{D}_{1}$ (drug 1) and $\mathrm{D}_{2}$ (drug 2 ) alone that gives $x \%$ of cell viability inhibition, whereas (D) ${ }_{1}$ and (D) 2 are the doses of drug 1 and drug 2 in combination that also inhibited $\mathrm{x} \%$ of cell viability. Hence, $\mathrm{CI}<1, \mathrm{CI}=1$, and $\mathrm{CI}>1$ indicate, respectively, synergism, additive and antagonism effect of the drugs association.

\subsection{Apoptosis assay}

For apoptosis measurements, cells were plated in 6-well culture plates and exposed to oxaliplatin $(10,5$ and $2.5 \mu \mathrm{M})$ alone or combined with $10 \mu \mathrm{M}$ of LabMol-12 for $24 \mathrm{~h}$. Then $5 \mu \mathrm{L}$ of Annexin V-FITC and $1 \mu \mathrm{L}$ of the $100 \mu \mathrm{g} / \mathrm{mL}$ PI were added to each $100 \mu \mathrm{L}$ of cell suspension in an appropriated buffer. The analysis was performed by flow cytometry (FACSCalibur, BD Biosciences, CA, USA), measuring the fluorescence emission at $530 \mathrm{~nm}$ and $>575 \mathrm{~nm}$ and flow data was analyzed using FlowJo software (Tree Star, OR, USA).

\subsection{Cell cycle}

Cells were seed in 6-well plates and, after their adhesion, they were treated for $24 \mathrm{~h}$ with oxaliplatin $(10,5$ and $2.5 \mu \mathrm{M})$ alone or combined with $10 \mu \mathrm{M}$ of LabMol-12 for $24 \mathrm{~h}$. Then, cells were collected, fixed with cold $70 \%$ ethanol and stored at $-20^{\circ} \mathrm{C}$. Cells were washed, resuspended in PBS and incubated at $37^{\circ} \mathrm{C}$ for $45 \mathrm{~min}$ with $10 \mathrm{mg} / \mathrm{mL}$ of RNase and $1 \mathrm{mg} / \mathrm{mL}$ of PI. Flow cytometric 
analysis was performed using a FACScan flow cytometry system (FACSCalibur, BD Biosciences, CA, USA). Cellular proliferation analysis was carried out using WinMDI Version 2.8. The percentage of cells in the different cell cycle phases was determined using Modfit LT software (Verity Software House, Topsham, ME).

\subsection{Mitochondrial membrane potential}

Cells were seeded in 6-well plates and treated with oxaliplatin $(10,5$ and $2.5 \mu \mathrm{M})$ alone or combined with $10 \mu \mathrm{M}$ of LabMol-12 for $24 \mathrm{~h}$ after their adhesion. Tetramethylrhodamine ethyl ester (TMRE) was used to assess changes in mitochondrial membrane potential $(\Delta \mathrm{Ym})$ observed in apoptotic cells. Cells were incubated for $20 \mathrm{~min}$ at $37^{\circ} \mathrm{C}$ with $25 \mu \mathrm{g} / \mathrm{mL}$ TMRE before analysis performed by flow cytometry in FACSCalibur, measuring the fluorescence emission and flow data were analyzed using FlowJo software (Tree Star, OR, USA).

\subsection{D matrigel culture}

Cell culture plate was coated with $50 \mu \mathrm{L}$ of Matrigel per well and then placed at $37^{\circ} \mathrm{C}$ for $30 \mathrm{~min}$. Cells were plated at a concentration of cells $10^{5} /$ well in complete culture medium and incubated for 2 days. Afterward, cells were treated with oxaliplatin $(10,5$ and $2.5 \mu \mathrm{M})$ alone or combined with $10 \mu \mathrm{M}$ of LabMol-12 for $24 \mathrm{~h}$. The culture was examined and photographed under the microscope.

\subsection{Western blot}

Cells were exposed to oxaliplatin (10, 5 and $2.5 \mu \mathrm{M})$ alone or combined with $10 \mu \mathrm{M}$ of LabMol-12 for $24 \mathrm{~h}$. Following treatments, cells were collected, centrifuged, washed twice with icecold PBS and whole-cell lysates were obtained by suspending the cells in a lysis buffer at $4-8^{\circ} \mathrm{C}$. Lysates were centrifuged at $13,000 \times \mathrm{g}$ for $10 \mathrm{~min}$ at $4{ }^{\circ} \mathrm{C}$, and the supernatant fractions were collected. Protein concentrations were determined by the Bradford assay. Aliquots of each sample were subjected to SDS-PAGE with a $4 \%$ to $20 \%$ gradient for protein separation and electro-transferred to polyvinylidene difluoride (PVDF) membranes. The membranes were blocked with blocking buffer ( $0.1 \%$ Triton X-100 with 5\% nonfat dry milk in TBS-Tween 20) for $60 \mathrm{~min}$. After washing with TBS-T, membranes probed with the following primary caspase- 3 antibody or $\beta$ actin (diluted in TBS-Tween 20 solution containing
$2.5 \%$ dry milk, and incubated at $4-8{ }^{\circ} \mathrm{C}$ overnight). After washing in TBS-Tween 20, the membranes were incubated with horseradish peroxidase conjugated anti-rabbit or anti-mouse secondary antibody. The blots were visualized with a FluorChem 8900 Imager and quantified by a densitometer using the Alpha Imager application program (Alpha Innotech, San Leandro, CA).

\subsection{Statistical analysis}

Statistical analysis was performed in Graph-Pad Prism software, version 5.04 (LaJolla, CA, USA). Differences with $\mathrm{p}<0.05$ were considered statistically significant. The results are expressed as the mean \pm SD. The one-way ANOVA followed by Turkey's was performed to compare differences between three or more groups.

\subsection{Molecular modeling approach}

The three-dimensional (3D) molecular model of LabMol-12 was built in its neutral form using Spartan 08' software (Wavefunction, Inc. Irvine, $\mathrm{CA}$ ). The 3D crystal structure available of oxaliplatin in Protein Data Bank (PDB entry: 1PG9) [27] was employed as the starting geometry. The software ORCA 3.0.2 [28] was used to perform the geometry optimization and energy minimization. Each structure was fully optimized in vacuum at the DFT level, without imposing constraints, using B3LYP [29] hybrid functional with the $6-31 \mathrm{G}^{*}[30]$ basis set for $\mathrm{H}, \mathrm{C}, \mathrm{N}, \mathrm{O}$ atoms and LANL2DZ [31] pseudopotential and associated basis set for the transition metals (Pt).

The optimized 3D structure of both compounds was used as starting geometries to calculate the molecular properties. Single point calculations were performed in Spartan $08^{\prime}$ (Wavefunction, Inc. Irvine, CA). For LabMol-12, the calculations were executed in vacuum using B3LYP [29] hybrid functional with 6-311G* [30] basis set, setting the program to compute orbitals and energies, atomic charges and converge the result. For oxaliplatin, the chosen basis was $6-31+G^{*}[30]$, which include LANL2DZ [31] and associated basis set for transition metals, to perform the calculations for $\mathrm{Pt}$ atom present in this structure; the software was configured to compute orbitals and energies, atomic charges, pseudopotential and converge the result [32]. Single point calculations provided the following properties: dipole moment $(\mu)$, molecular orbital

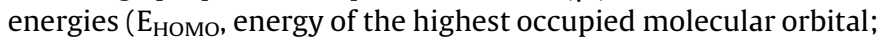
$\mathrm{E}_{\mathrm{LUMO}}$, energy of the lowest unoccupied molecular orbital), and the surfaces: molecular orbital maps HOMO and LUMO, electron-
A

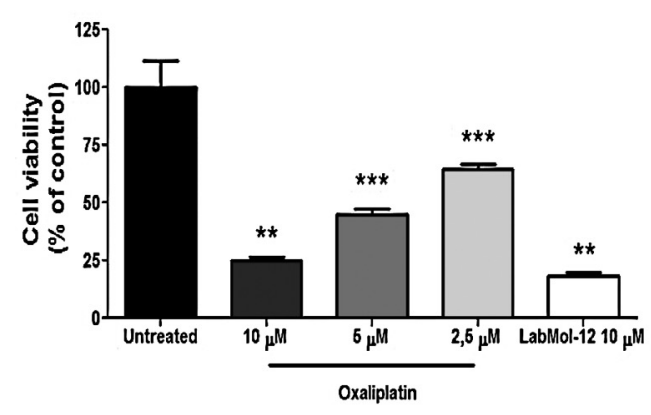

B

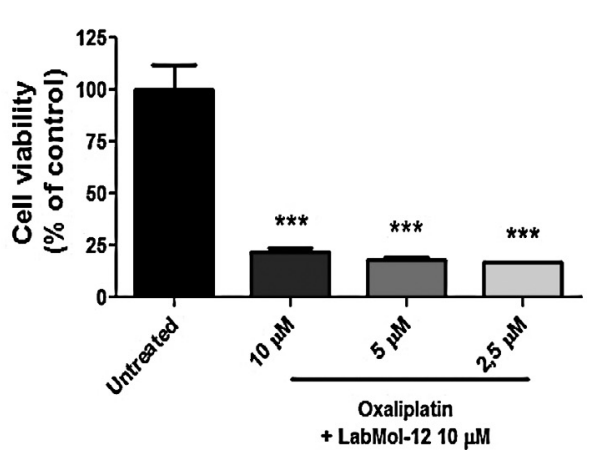

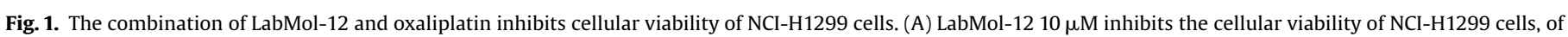

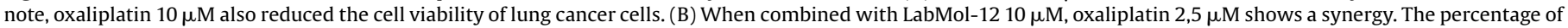

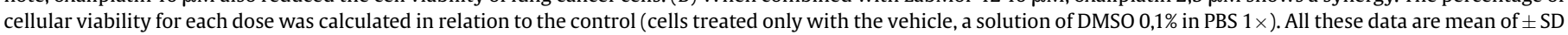
$(\mathrm{n}=3) .^{* *} \mathrm{p}<0.001$ versus control and ${ }^{* * *} \mathrm{p}<0.01$ versus control. 
density maps for HOMO and LUMO orbitals and molecular electrostatic potential maps (MEP). Also, we calculated octanol/ water partition coefficient ( $\log P$ ), which is a hydrophobicity measure, using a Calculator Plugin implemented on Marvin 6.3.1, 2014, Chem Axon (http://www.chemaxon.com).

\section{Results}

\subsection{LabMol-12 inhibits cellular viability of NCI-H1299 cells}

To evaluate cytotoxic effects of LabMol-12 on NCI-H1299 cells, a colorimetric MTT assay was performed. Our finding shows that LabMol-12 alone at the concentration of $10 \mu \mathrm{M}$ is capable of reducing the cellular viability in $\mathrm{NCI}-\mathrm{H} 1299$ cells. Of note, oxaliplatin also reduces cell viability of $\mathrm{NCI}-\mathrm{H} 1299$ cells at all concentrations tested (Fig. 1). Importantly, the combination of LabMol-12 $10 \mu \mathrm{M}$ with oxaliplatin in all doses tested induced cytotoxicity. Notably, oxaliplatin at the concentration of $2.5 \mu \mathrm{M}$ shows the maximum effect when used with LabMol-12. These results suggest that oxaliplatin can be combined with LabMol-12 in lower doses with no loss of cytotoxicity effects.

\subsection{LabMol-12 inhibits NCI-H1299 cells growth}

We also evaluated whether LabMol-12 inhibits NCI-H1299 cellular growth. For this purpose, NCI-H1299 cells were growing in medium supplied with $10 \%, 20 \%$ or serum starvation. As shown in Table 1 LabMol-12 inhibits cell growth after $72 \mathrm{~h}$ of treatment. Of interest, LabMol-12 produces inhibitory effects of NCI-H1299 cells in all cell culture conditions. Indeed, oxaliplatin in all concentrations tested inhibits cells growth in those cells supplied with $10 \%$ and $20 \%$. In contrast, cells treated with oxaliplatin $10 \mu \mathrm{M}$ with serum starvation, oxaliplatin did not inhibit their growing. Importantly, we observed that when cells were cultured in $20 \%$ of FBS, the combination of LabMol-12 and oxaliplatin notably inhibits the growth of NCI-H1299 cells. These findings provide preliminary evidence that the combination is more sensitive to the cells in higher proliferation.
3.3. LabMol-12 induces arrest at GO/G1 phase of cells cycle in the NCIH1299 cells

We also evaluated if LabMol-12 and oxaliplatin have effects over the cellular distribution through the cell cycle. The cells were previously pre-treated with serum starvation for $12 \mathrm{~h}$, which synchronizes cells in G0/G1 and, then, the cells were treated for $24 \mathrm{~h}$. Interestingly, LabMol-12 induced G0/G1 phase arrest in NCIH1299 cells, but oxaliplatin $5 \mu \mathrm{M}$ had no effect on cellular distribution through cell cycle phases. None of the associations of LabMol-12 and oxaliplatin improved this effect of LabMol-12 (Fig. 2).

\subsection{LabMol-12 presents synergism with oxaliplatin in lower doses}

To further evaluate the combination index $(\mathrm{CI})$, we performed the MTT assay using LabMol-12 and oxaliplatin. Of note, data from MTT assay were analyzed by the Compusyn software. The plotted graphics show the fraction of NCI-H1299 cells affected by the treatment (Fa), in other words, cells which had a reduction of the cell viability. Indeed, the logarithmic of this graphic is shown (Fig. 3). According to Compusyn analysis, there is a synergic effect between oxaliplatin 2.5 and $5 \mu \mathrm{M}$ when combined with LabMol12. In contrast, LabMol-12 and oxaliplatin $10 \mu \mathrm{M}$ had an antagonist effect (Table 2). Altogether, these findings suggest that LabMol-12 and oxaliplatin have synergic effects against NCI-H1299 cells.

\subsection{LabMol-12 induces cell death in the NCI-H1299 cells}

To further investigate the mechanism of cytotoxicity induced by LabMol-12, externalization of phosphatidylserine was evaluated. As shown in Fig. 4A, LabMol-12 and their combination with oxaliplatin induced apoptosis of NCI-H1299 cells. Of note, the treatment with oxaliplatin $2.5 \mu \mathrm{M}$ and the LabMol-12 $10 \mu \mathrm{M}$ also induced cell death by apoptosis in NCI-H1299 cells. In order do better evaluate if apoptosis induced by LabMol-12 and oxaliplatin is caspase-dependent, then we pre-treated the cells with a pancaspase inhibitor, Z-VAD-FMK. We found that the lack of caspases reduced cytotoxic effects of LabMol-12 and oxaliplatin against NCI-

Table 1

NCI-H1299 cells' growth through the treatments, using 1,10 or $20 \%$ of FBS.

\begin{tabular}{|c|c|c|}
\hline Condition & FBS (\%) & Percentage of cell growth \pm SD \\
\hline Untreated & 1 & $100.00 \pm 3.2$ \\
\hline LabMol-12 $10 \mu \mathrm{M}$ & & $0 \pm 0.2$ \\
\hline Oxaliplatin $10 \mu \mathrm{M}$ & & $28.58 \pm 1.1$ \\
\hline Oxaliplatin $5 \mu \mathrm{M}$ & & $35.71 \pm 0.3$ \\
\hline Oxaliplatin $2.5 \mu \mathrm{M}$ & & $128.58 \pm 5.3$ \\
\hline Oxaliplatin $10 \mu \mathrm{M}+$ LabMol-12 $10 \mu \mathrm{M}$ & & $42.86 \pm 1.3$ \\
\hline Oxaliplatin $5 \mu \mathrm{M}+$ LabMol-12 $10 \mu \mathrm{M}$ & & $64.28 \pm 2.6$ \\
\hline Oxaliplatin $2.5 \mu \mathrm{M}+$ LabMol-12 $10 \mu \mathrm{M}$ & & $85.71 \pm 1.6$ \\
\hline Untreated & 10 & $207.14 \pm 7.0$ \\
\hline LabMol-12 $10 \mu \mathrm{M}$ & & $0 \pm 0.1$ \\
\hline Oxaliplatin $10 \mu \mathrm{M}$ & & $78.57 \pm 1.4$ \\
\hline Oxaliplatin $5 \mu \mathrm{M}$ & & $42.86 \pm 0.9$ \\
\hline Oxaliplatin $2.5 \mu \mathrm{M}$ & & $57.14 \pm 0.5$ \\
\hline Oxaliplatin $10 \mu \mathrm{M}+$ LabMol-12 $10 \mu \mathrm{M}$ & & $35.71 \pm 2.6$ \\
\hline Oxaliplatin $5 \mu \mathrm{M}+$ LabMol-12 $10 \mu \mathrm{M}$ & & $42.86 \pm 0.7$ \\
\hline Oxaliplatin $2.5 \mu \mathrm{M}+$ LabMol-12 $10 \mu \mathrm{M}$ & & $92.86 \pm 4.0$ \\
\hline Untreated & 20 & $150.00 \pm 1.2$ \\
\hline LabMol-12 $10 \mu \mathrm{M}$ & & $0 \pm 0.5$ \\
\hline Oxaliplatin $10 \mu \mathrm{M}$ & & $21.43 \pm 2.7$ \\
\hline Oxaliplatin $5 \mu \mathrm{M}$ & & $28.57 \pm 2.0$ \\
\hline Oxaliplatin $2.5 \mu \mathrm{M}$ & & $28.57 \pm 0.8$ \\
\hline Oxaliplatin $10 \mu \mathrm{M}+$ LabMol-12 $10 \mu \mathrm{M}$ & & $21.43 \pm 1.8$ \\
\hline Oxaliplatin $5 \mu \mathrm{M}+$ LabMol-12 $10 \mu \mathrm{M}$ & & $42.86 \pm 2.7$ \\
\hline Oxaliplatin $2.5 \mu \mathrm{M}+$ LabMol-12 $10 \mu \mathrm{M}$ & & $28.57 \pm 3.0$ \\
\hline
\end{tabular}




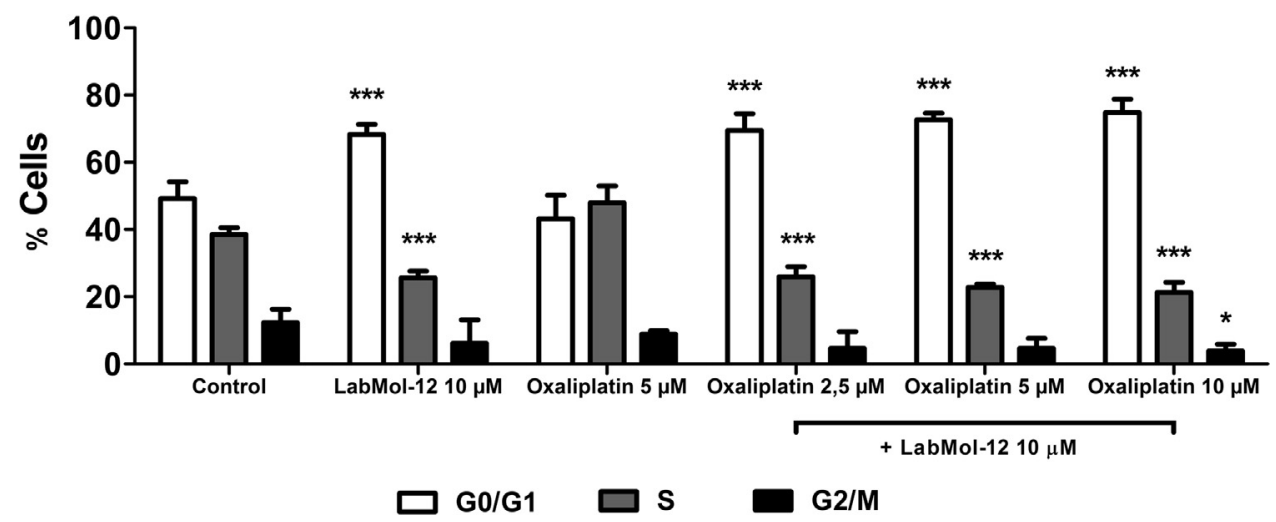

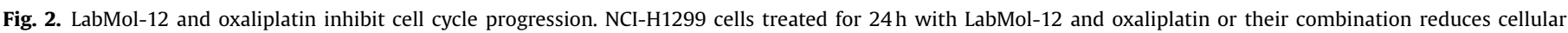

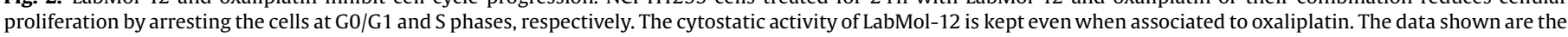
means \pm SD from three independent experiments. ${ }^{*} \mathrm{p}<0.05$ and ${ }^{* * *} \mathrm{p}<0.01$ versus the same cell cycle phase of control group.

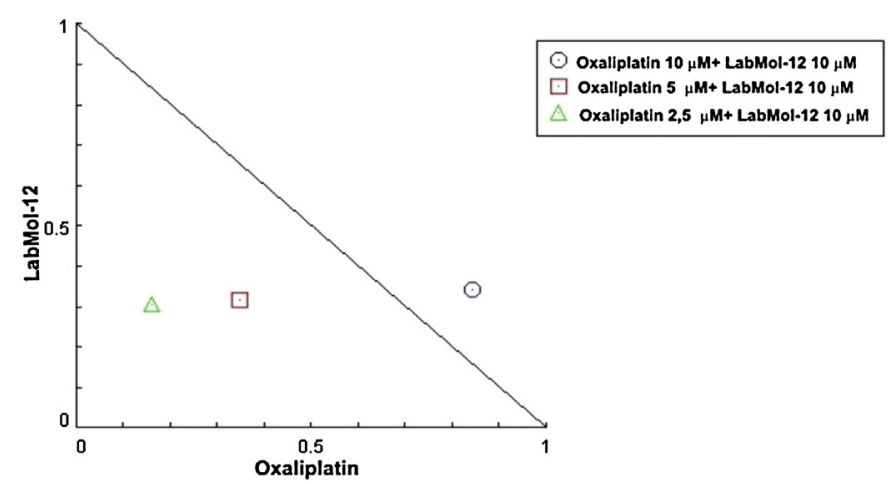

Fig. 3. LabMol-12 synergically enhances the activity of oxaliplatin against NCIH1299 lung cancer cells. NCI-H1299 cells were seed at a density of $10^{4}$ cells/well in 96-wells plates and treated for $24 \mathrm{~h}$ with LabMol-12 and oxaliplatin in monotherapy or combined with different concentrations. The cell viability was evaluated using MTT assay. The data were analyzed using the software Compusyn resulting in the combination index $(\mathrm{CI})$ values and the normalized isobologram. Normalized isobologram for the combination of LabMol-12 $10 \mu \mathrm{M}$ with oxaliplatin 2.5, 5 and $10 \mu \mathrm{M}$ in NCI-H1299 cells shows the association of LabMol-12 $10 \mu \mathrm{M}$ with oxaliplatin 2.5 and $5 \mu \mathrm{M}$, represented as a green triangle and a red square respectively, result in a $\mathrm{CI}$ value under 1 , which represents a synergic association. Though, LabMol-12 $10 \mu \mathrm{M}$ with oxaliplatin $10 \mu \mathrm{M}$, represented as a blue circle, resulted in a $\mathrm{CI}$ value superior a 1 , which is related to an antagonistic association. All these data are mean of three independent experiments.

Table 2

Combination Index $(\mathrm{CI})$ of LabMol-12 $(10 \mu \mathrm{M})$ associated to oxaliplatin (2.5, 5 and $10 \mu \mathrm{M})$ in NCI-H1299 cells.

\begin{tabular}{lll}
\hline $\begin{array}{l}\text { LabMol-12 } \\
(\mu \mathrm{M})\end{array}$ & $\begin{array}{l}\text { Oxaliplatin } \\
(\mu \mathrm{M})\end{array}$ & $\mathrm{CI}$ \\
\hline 10.0 & 10.0 & 1.118 \\
10.0 & 5.0 & 0.664 \\
10.0 & 2.5 & 0.47 \\
\hline
\end{tabular}

H1299 cells analyzed by MTT assay. It thus can suggest that LabMol-12 and oxaliplatin can trigger apoptosis is caspasedependent manner (Fig. 4B). Additionally, we also investigated whether caspase- 3 is related to apoptosis induced by LabMol-12 and oxaliplatin or their combination. We also evaluated NCI-H1299 cells, by MTT assay, pretreated with BAPTA, a blocker of DNA fragmentation and chromatin condensation, both downstream of caspase-3 activation during apoptosis. Our finding indicates that BAPTA did not significantly inhibit apoptosis induction by LabMol12 and oxaliplatin (Fig. 4C). Indeed, the detection of caspase-3 by western blotting reveals that the treatment with LabMol-12 and oxaliplatin increase the caspase-3 expression (Fig. 4D). Moreover, we monitored changes in $\Delta \psi \mathrm{m}$, then, $\mathrm{NCI}-\mathrm{H} 1299$ cells were treated and stained with TMRE, a cationic fluorophore that accumulates into mitochondria in response to the negative $\Delta \psi \mathrm{m}$ (Fig. $4 \mathrm{E}$ ). Of interest, results show that the treatment with the combination by LabMol-12 $10 \mu \mathrm{M}$ and oxaliplatin $10 \mu \mathrm{M}$ trigger a collapse of $\Delta \psi \mathrm{m}$, an early event associated with apoptosis. These results indicate the combination of LabMol-12 and oxaliplatin induces apoptosis.

3.6. LabMol-12 and the combination with oxaliplatin causes cytotoxic effects in 3D culture of NCI-H1299 cells

Three-dimensional (3D) cell culture systems were employed to take advantages in providing more physiologically relevant information and more predictive data of cytotoxic effects of LabMol-12 and the combination with oxaliplatin on NCI-H1299 cells. In agreement with the results in monolayer culture (2D), in 3D culture, cells exposed to LabMol-12 alone or associated to oxaliplatin showed morphological features of apoptosis, such as cytoplasm shrinks and cell swelling, which, its indicates cell skeleton is disassembled, broken off bits of the membrane, and apoptotic bodies as is it show by the black arrows (Fig. 5).

\subsection{Molecular modeling findings}

The purpose of molecular modeling approach was to find the optimized geometries for LabMol-12 and oxaliplatin, to calculate molecular properties, and to shed some light on the synergic effect of the combination therapy and the structure-activity relationships. Table 3 shows the results of the calculated molecular properties $\left[\mathrm{E}_{\text {total }}, \mathrm{E}_{\mathrm{HOMO}}, \mathrm{E}_{\mathrm{LUMO}}, \mathrm{GAP}=\mathrm{E}_{\mathrm{HOMO}}-\mathrm{E}_{\mathrm{LUMO}}, \mu\right.$, and lipophilicity (ClogP)] for LabMol-12 and oxaliplatin. The electronic density distribution of LabMol-12 and oxaliplatin can be visualized through the MEPs. The higher electronic density (yellow to red) indicates negative regions (nucleophilic) while green to blue colors indicate positive regions (electrophilic). It is possible to note that the major electron density in oxaliplatin is around the oxalate leaving group, showing how reactive this group is and its importance on the reactivity of this anticancer compound. The higher electron density in LabMol-12 is distributed on the pyridine and indole rings, and on the carbonyl of the amide group bonded to cyclohexane ring (Fig. 6A-D).

The molecular orbital energies ( $\mathrm{E}_{\text {Hомо }}$ and $\mathrm{E}_{\mathrm{LUMO}}$; $\mathrm{kcal} / \mathrm{mol}$ ), as well as the difference between them ( $\mathrm{GAP}=\mathrm{E}_{\mathrm{HOMO}}-\mathrm{E}_{\mathrm{LuMO}}$; $\mathrm{kcal} /$ $\mathrm{mol}$ ), were computed for the selected optimized-energy conformation of each molecule and were listed in Table 3. The distribution of the molecular orbital maps HOMO and LUMO are 
A
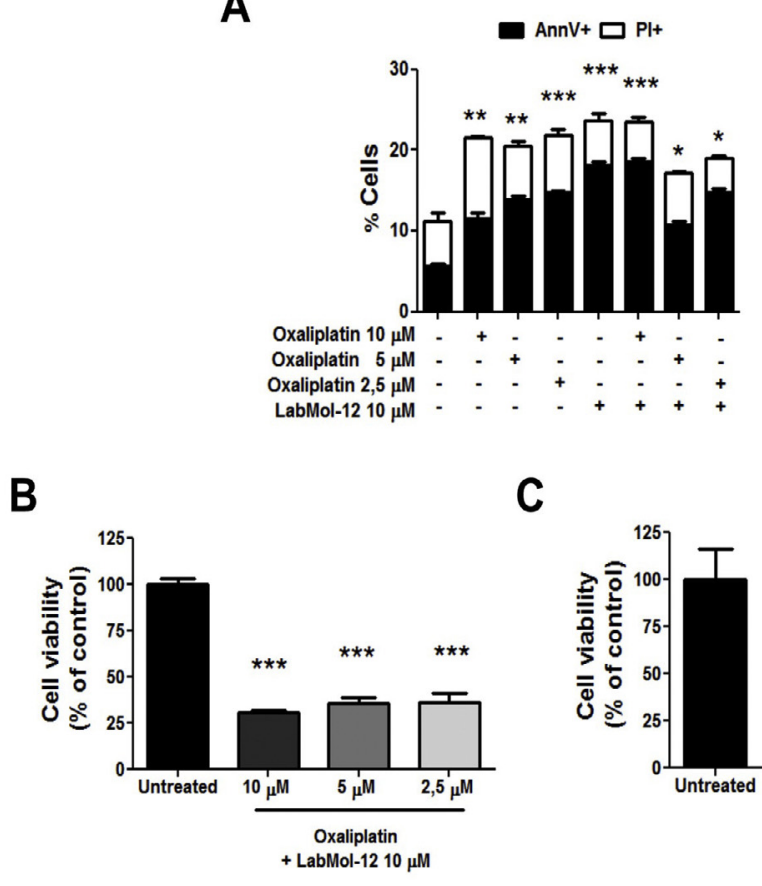

C
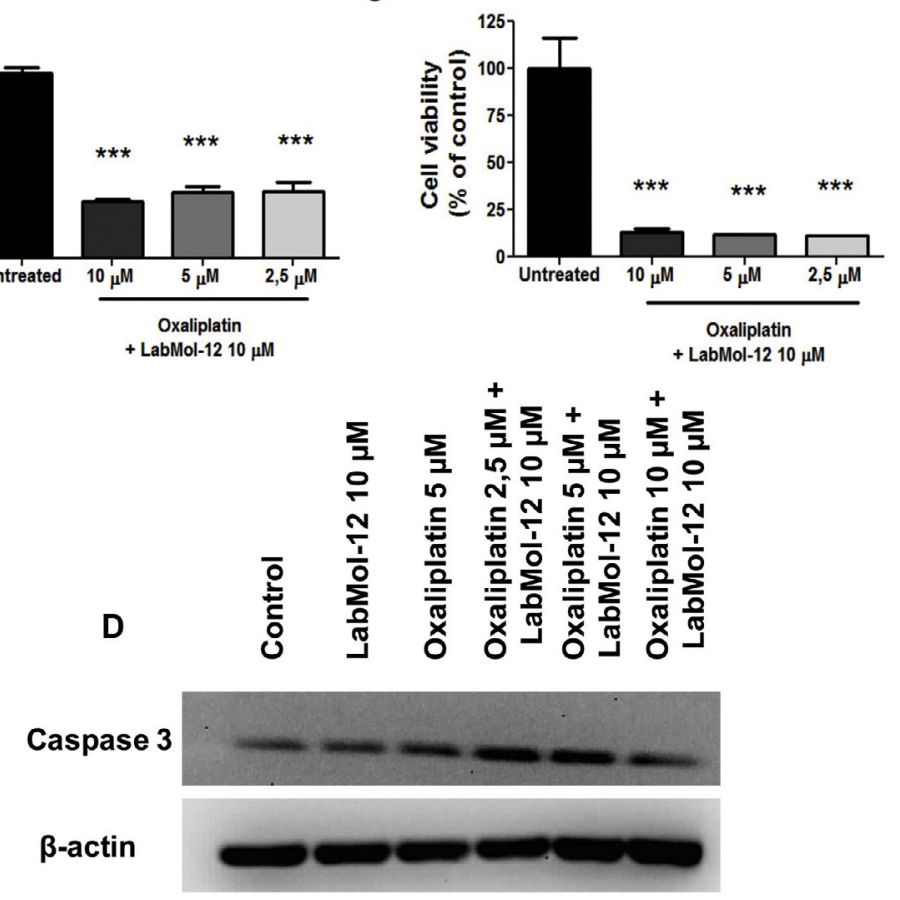

$\mathbf{E}$
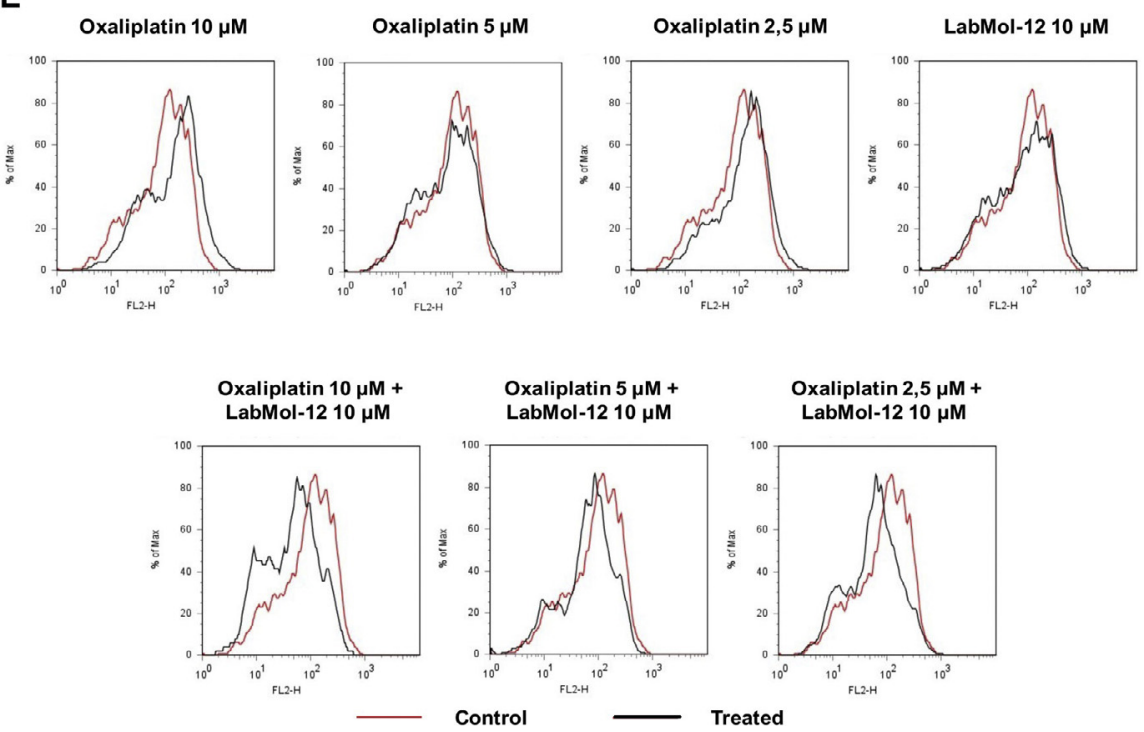

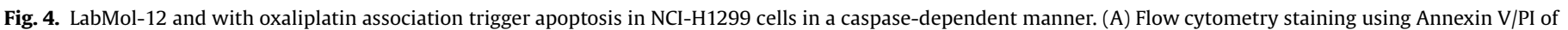

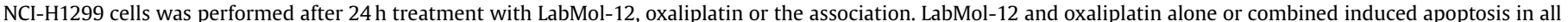

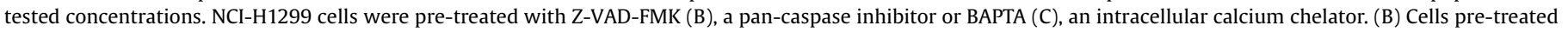

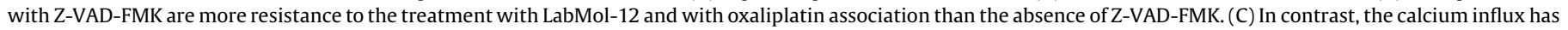


Untreated

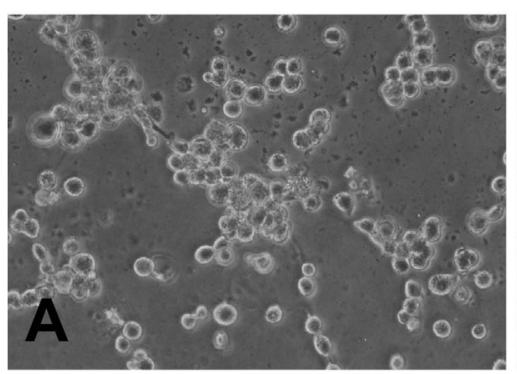

LabMol-12 $10 \mu \mathrm{M}$

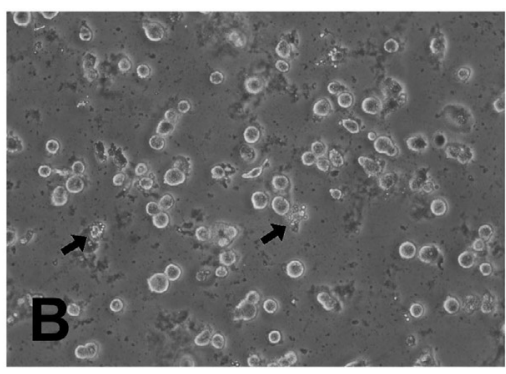

Oxaliplatin $5 \mu \mathrm{M}$

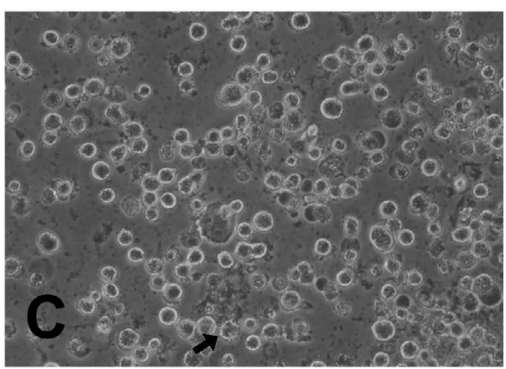

\section{Oxaliplatin $10 \mu \mathrm{M}+$ LabMol-12 $10 \mu \mathrm{M}$}

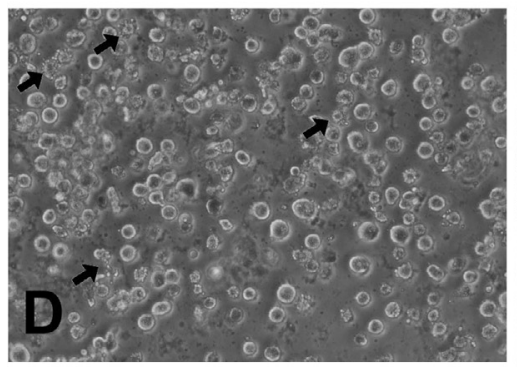

\section{Oxaliplatin $5 \mu \mathrm{M}+$ LabMol-12 $10 \mu \mathrm{M}$}

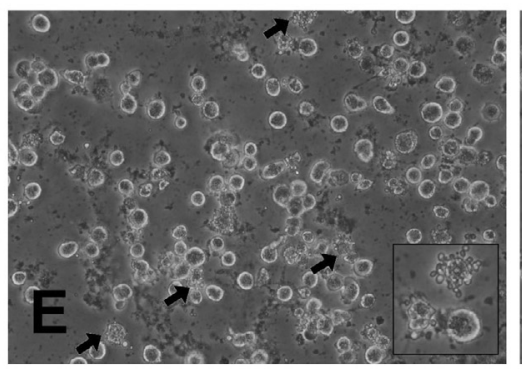

\section{Oxaliplatin 2,5 $\mu \mathrm{M}+$ LabMol-12 $10 \mu \mathrm{M}$}

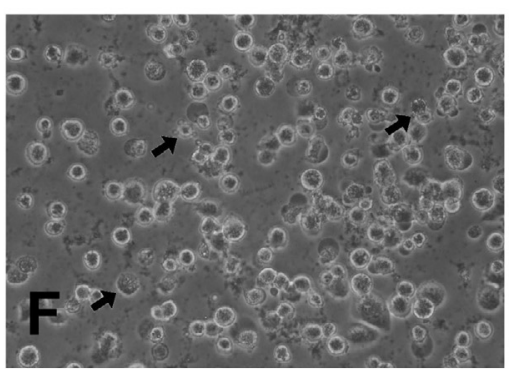

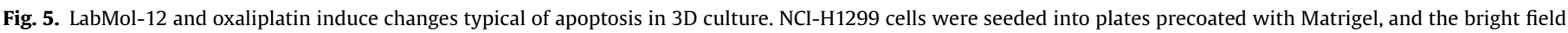

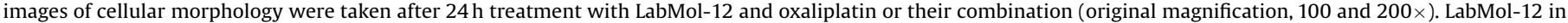

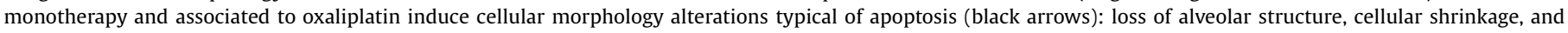
cellular agglomeration. The images are representative of three independent experiments.

Table 3

Calculated molecular properties for LabMol-12 and oxaliplatin.

\begin{tabular}{|c|c|c|c|c|c|c|}
\hline & $\begin{array}{l}\mathrm{E}_{\text {total }} \\
(\mathrm{kcal} / \mathrm{mol})\end{array}$ & $\begin{array}{l}\mathrm{E}_{\text {Hомо }} \\
(\mathrm{kcal} / \mathrm{mol})\end{array}$ & $\begin{array}{l}\mathrm{E}_{\text {LUMO }} \\
\text { (kcal/mol) }\end{array}$ & $\begin{array}{l}\text { GAP } \\
(\mathrm{kcal} / \mathrm{mol})\end{array}$ & $\begin{array}{l}\mu \\
\text { (Debye) }\end{array}$ & $C \log P$ \\
\hline LabMol-12 & -816342.02 & -129.94 & -16.73 & -113.21 & 2.85 & 3.61 \\
\hline Oxaliplatin & -528926.61 & -119.95 & -10.73 & -109.22 & 10.65 & 1.73 \\
\hline
\end{tabular}

shown in Fig. 7A-D, whereas the electron-density maps HOMO and LUMO are shown in Fig. 8A-D. The GAP value $\left(\mathrm{E}_{\mathrm{HOMO}}-\mathrm{E}_{\mathrm{LUMO}}\right)$ points out that LabMol-12 is more reactive than oxaliplatin due to its electronegativity character. The hydrophobic property was calculated through the $n$-octanol/water partition coefficient $(\mathrm{ClogP})$ and is an important physicochemical property in drug discovery campaigns (Table 3 ).

\section{Discussion}

In fact, platinum drugs are critical tools in cancer therapy, mainly in lung cancer cases. However, their toxic side effects remain a huge obstacle to patient's quality of life. Oxaliplatin, by its turn, has the neurotoxicity as its major drawback, and this is often the cause of treatment discontinuation $[33,34]$. In this regard, new approaches for lung cancer therapy must be found to, at least, reduce the doses of oxaliplatin, and, therefore, its side effects.
In the present study, we investigated the cytotoxic effect of LabMol-12 on NCI-H1299 cells in monolayer and 3D cell culture. Our data showed that LabMol-12 $10 \mu \mathrm{M}$ by itself reduces cell viability and induces cell death by apoptosis, as well as oxaliplatin. Others inhibitors of also Raf-MEK-ERK signaling showed interesting cytotoxic effects and they were evaluated clinically for melanoma, leukemia and NSCLC [35]. Interestingly, the combination of LabMol-12 and oxaliplatin reduces cell growth of NCIH1299, which in its turn, indicates that LabMol-12 and oxaliplatin show synergic effects to the cells in higher proliferation. These findings provide preliminary evidence that the combination has a cytostatic effect against to NCI-H1299 cells. LabMol-12 does not present a strong activity in those cells with rapidly growing cells, indicating that LabMol-12 is mainly cytotoxic. Importantly, LabMol-12 and oxaliplatin at the concentration of $2.5 \mu \mathrm{M}$ were able to reduce cell viability of $\mathrm{NCI}-\mathrm{H} 1299$ cells. Also, according to CI data, the combination of LabMol-12 and oxaliplatin is synergistic 
(a)<smiles>O=C1O[Pb]2(N[C@H]3CCCC[C@H]3N2)OC1=O</smiles>

(c)<smiles>O=C(NC(Cc1c[nH]c2ccccc12)C(=O)Nc1ccncc1)C1CCCCC1</smiles>

(b)

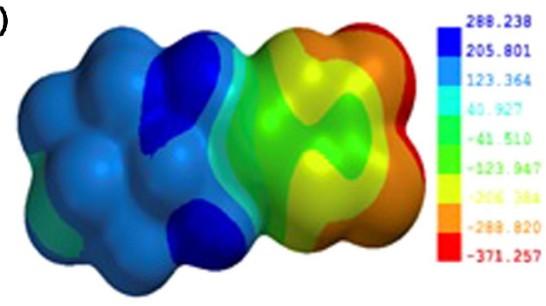

(d)

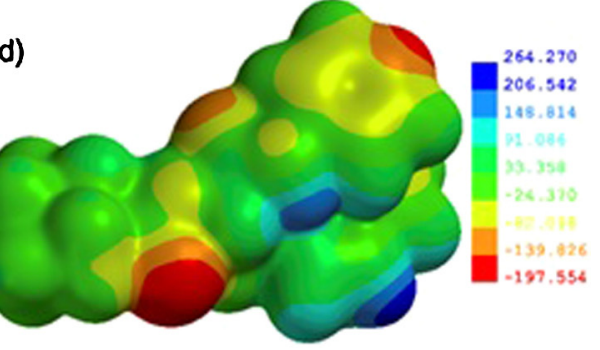

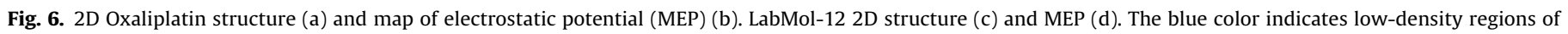
electrons and red colors denotes rich electronic regions.

(a)

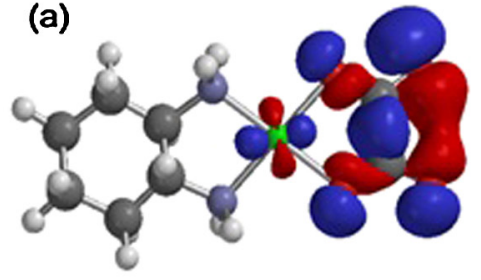

(c)

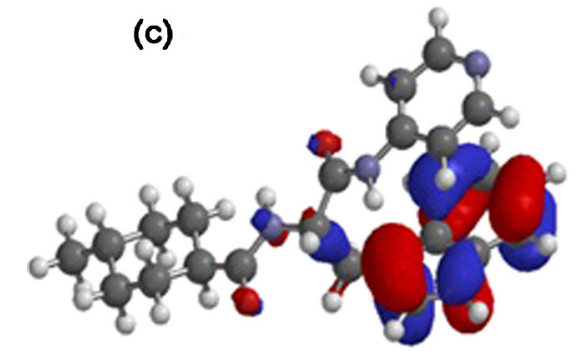

(b)
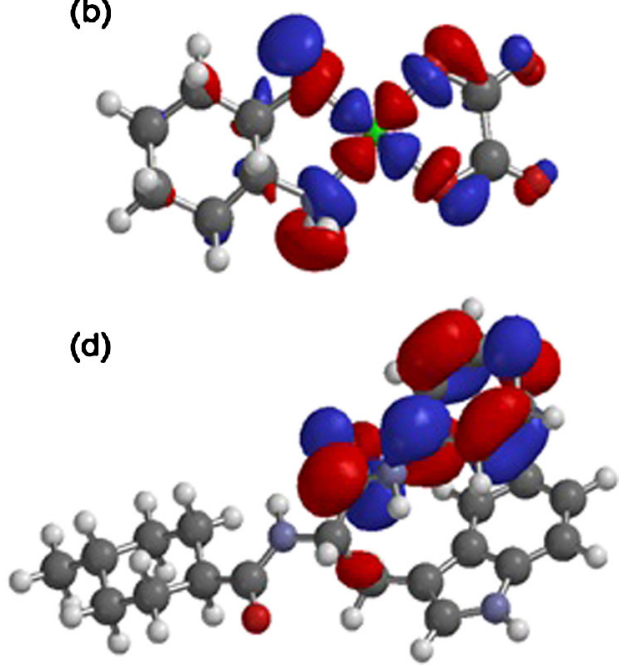

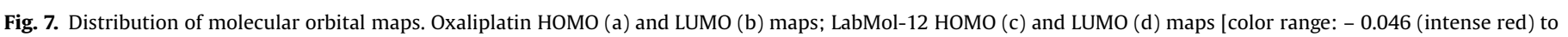

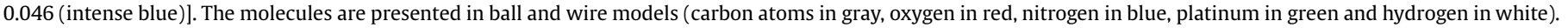

(a)
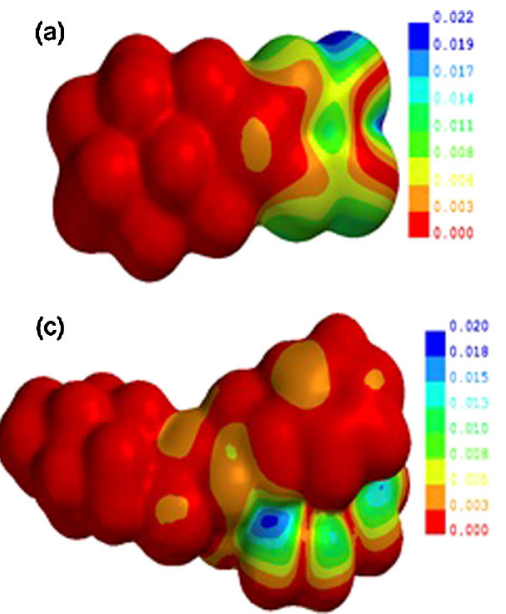

(b)

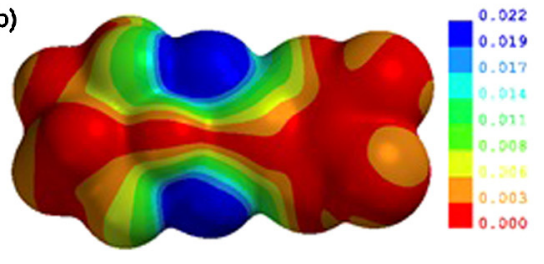

(d)

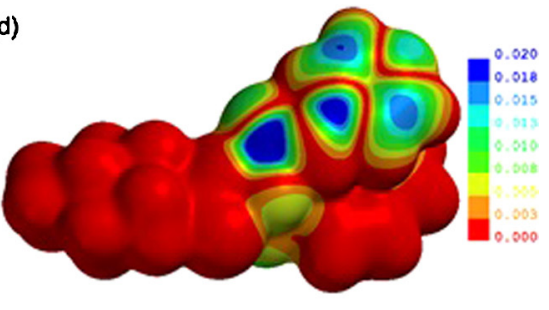

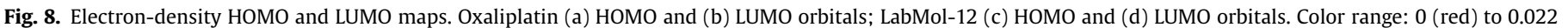
(blue). 
and also reduces the cellular viability of NCI-H1299 cells. It can thus indicate that in this dose, the combination can affect the cells growth. The first farnesyltransferase inhibitors to undergo clinical testing, SCH66336, also have shown additive and synergistic effects by enhancing apoptose in combination with a platina derivative in sevral cancer cell lines [36].

It is noteworthy that 3D culture provides more relevant information during drug-screening process, due to its closeness to the physiological environment, such as, maintenance of the morphology, the tissue-related functions, the biosynthesis of drugmetabolizing enzymes and the cell-cell and cell-extracellular matrix interactions [37,38]. Accordingly, the 3D culture data corroborates with monolayer results. It shows that LabMol-12 alone and in association with different oxaliplatin doses could produce a variety of apoptotic effects in in vitro three-dimensional tumor microenvironment. These data taken together indicate LabMol-12 as a promising hit for NSCLC treatment and a possible drug for oxaliplatin doublet chemotherapy.

Overall, tumor cells of different colonies can be more sensible to chemotherapy agents. Although, proliferative tumor cells in a continuous exponential phase, are more susceptible to drugs [39]. The results showed that, the effect of the combination of LabMol12 and oxaliplatin is more effective when the cells have a proliferative capacity. Notably, the combination is more effective to NCI-H1299 cells cultured in FBS 20\%. This observation suggests that the combination can kill cells more effectively during certain phases of cells cycle [40]. Since, data of present study showed that LabMol-12 and oxaliplatin inhibit cell growth, we next investigated whether the progression of cells through cell cycle could be affected. Taking this into account, it is reasonable to suggest that therapeutic combination of LabMol-12 and oxaliplatin inhibits cell cycle progression of $\mathrm{NCI}-\mathrm{H} 1299$ cells. In agreement with our hypothesis, the anti-proliferative effects of LabMol-12 and oxaliplatin occur through the blockage at the G1/S transition. To the best of our knowledge, the combination produced a cell cycle specific effects. This assumption is based on the fact that some chemotherapy drugs can kill tumor cells in sensitive phase of cells cycle, such as S-phase. This finding has important implications for the understanding of the synergic effects of LabMol-12 and oxaliplatin. LabMol-12 effects in cell cycle are related to Ras-GTP positive regulation of cell growth, stimulating $S$ phase start which was evidenciated preavisouly by genetic modulation [41].

Moreover, data demonstrated that NCI-H1299 cells were arrested at G0/G1 phase by the combination of LabMol-12 and oxaliplatin, we investigated if apoptosis is mechanism outcome. Our data clearly showed that the reduction of $\Delta \psi \mathrm{m}$ in NCI-H1299 cells is a first evidence that LabMol-12 and oxaliplatin may trigger apoptosis by the intrinsic pathway. Of note, the mitochondrial membrane depolarization is followed by an increase of externalization of phosphatidylserine, a hallmark of apoptosis [42]. Indeed, in this study, the increase of caspase-3 correlates with the reduction of $\Delta \psi \mathrm{m}$, indicating that biochemical and morphological changes, typical of apoptosis observed in the 3D culture can be mediated by a caspase-3 [43]. Interestingly, Z-VAD-FMK, a pancaspase inhibitor, and BAPTA, a blocker of DNA fragmentation, we confirmed that LabMol-12 and oxaliplatin induce apoptosis in a caspase-dependent manner in the NCI-H1299 cells.

In the molecular modeling study, we aimed to calculate molecular and electronic properties of LabMol-12 and oxaliplatin to shed some light on the synergic effect of the combination therapy and the structure-activity relationships. There are three major parameters of critical importance in the intermolecular interactions those underlies ligand-receptor binding: electronic, hydrophobic and steric properties. Studies using electronic parameters show that electronic profile of molecules is directly related to their reactivities and biological activities. Molecular orbital fields are useful quantum chemical descriptors when an ionic or charge transfer reaction is part of the ligand-receptor interaction.

The dipole moment $(\mu)$ is related to the molecule's polarity. Moreover, the dipole moment provides useful information for the deduction of the molecular geometry of a molecule. From the values listed in Table 1, one can infer that LabMol-12 is more lipophilic and less polar than oxaliplatin, probably because the latter presents an oxalate' leaving group in its structure and is known that its hydrophobicity was improved adding the diaminocyclohexane ring to its structure. In fact, the oxaliplatin mechanism of action is uncommon, and the literature describes a link between its efficacy against colorectal cancer and particularities involving its interaction with proteins from diverse transport system through the cell membrane [44-46].

The LUMO and HOMO density maps show the electron density of HOMO and LUMO orbitals, describing the HOMO orbitals as an electron-donor region and LUMO orbitals as an electron-acceptor region of both molecules. Oxaliplatin's LUMO distribution map presents a $\pi$-antibonding orbital spread over the oxalate leaving group, which constitutes a particular electronic characteristic of this compound, with its less electrophilic character in comparison to cisplatin, could be related to its tumor selectivity and lack of cross-resistance supposedly displayed by this antineoplastic agent [45]. LabMol-12' LUMO distribution map is similar to the $\pi$-antibonding orbital observed in oxaliplatin, described by Dans and Coitiño (2009), indicating a possible synergic effect in their combined biological action. The $\mathrm{E}_{\mathrm{LUmo}}$ negative values show that both compounds can act as oxidants and can be reduced relatively easily [47].

\section{Conclusion}

In summary, this work evaluated the efficacy of LabMol-12 on NCI-H1299 cells as a new potential antineoplasic drug for NSCLC treatment. Our data suggest that LabMol-12 as a new hit for lung cancer treatment, once it, similarly to oxaliplatin, reduces cellular metabolic viability and induces cell death in NCI-H1299 cells both monolayer and 3D culture. Moreover, LabMol-12 allows reduction of oxaliplatin's doses when they are combined, thereby; it is a relevant strategy for reducing the side effects of oxaliplatin with the same response. Molecular modeling studies corroborated with the biological findings and suggested that the combination of LabMol-12 and oxaliplatin could have a synergistic effect.

\section{Conflict of interest}

The authors declare that they have no conflicts of interest concerning this article.

\section{Acknowledgements}

This work was supported by Sao Paulo Research Foundation (FAPESP), grant (2009/54599-5, 2013/07273-2, 2013/05396-0, 2014/07341-0, 2014/14267-1, 2014/24455-0 2015/18528-7 and 2016/05351-4) the National Counsel of Technological and Scientific Development (CNPq) and the State of Goiás Research Foundation (FAPEG).

\section{References}

[1] J. Ferlay, E. Steliarova-Foucher, J. Lortet-Tieulent, S. Rosso, J. Coebergh, H. Comber, D. Forman, F. Bray, Reprint of: cancer incidence and mortality patterns in Europe: estimates for 40 countries in 2012, Eur. J. Cancer 51 (9) (2015) 12011202. 
[2] R. Siegel, C. DeSantis, K. Virgo, K. Stein, A. Mariotto, T. Smith, D. Cooper, T. Gansler, C. Lerro, S. Fedewa, Cancer treatment and survivorship statistics, 2012 CA, Cancer J. Clin. 62 (4) (2012) 220-241.

[3] D.E. Gerber, J.H. Schiller, Maintenance chemotherapy for advanced non-smallcell lung cancer: new life for an old idea, J. Clin. Oncol. (2013) 43 (2012) 7459.

[4] G.V. Scagliotti, C. Kortsik, G.G. Dark, A. Price, C. Manegold, R. Rosell, M. O’Brien, P.M. Peterson, D. Castellano, G. Selvaggi, Pemetrexed combined with Oxaliplatin or carboplatin as first-line treatment in advanced non-small cell lung cancer: a multicenter, randomized, phase II trial, Clin. Cancer Res. 11 (2) (2005) 690-696.

[5] L.E. Raez, E.S. Santos, G. Lopes, M.F. Rosado, L.M. Negret, C. Rocha-Lima, K. Tolba, N. Farfan, K. Hamilton-Nelson, O. Silva, Efficacy and safety of oxaliplatin and docetaxel in patients with locally advanced and metastatic non-small-cell lung cancer (NSCLC), Lung Cancer 53 (3) (2006) 347-353.

[6] P. Bidoli, N. Zilembo, D. Cortinovis, L. Mariani, L. Isa, E. Aitini, D. Cullura, F. Pari, P. Nova, M. Mancin, Randomized phase II three-arm trial with three platinumbased doublets in metastatic non-small-cell lung cancer. An Italian trials in medical oncology study, Ann. Oncol. 18 (3) (2007) 461-467.

[7] C.H. Weissman, C.H. Reynolds, M.A. Neubauer, S. Pritchard, S. Kobina, L. Asmar A phase III randomized trial of gemcitabine?oxaliplatin versus carboplatinpaclitaxel as first-line therapy in patients with advanced non-small cell lung cancer, J. Thorac. Oncol. 6 (2) (2011) 358-364.

[8] A. Atmaca, S. Al-Batran, D. Werner, C. Pauligk, T. Güner, A. Koepke, H. Bernhard, T. Wenzel, A. Banat, P. Brueck, A randomised multicentre phase II study with cisplatin/docetaxel vs oxaliplatin/docetaxel as first-line therapy in patients with advanced or metastatic non-small cell lung cancer, Br. J. Cancer 108 (2) (2013) 265-270.

[9] S.-E. Al-Batran, J.T. Hartmann, S. Probst, H. Schmalenberg, S. Hollerbach, R. Hofheinz, V. Rethwisch, G. Seipelt, N. Homann, G. Wilhelm, Phase III trial in metastatic gastroesophageal adenocarcinoma with fluorouracil, leucovorin plus either oxaliplatin or cisplatin: a study of the arbeitsgemeinschaft internistische onkologie, J. Clin. Oncol. 26 (9) (2008) 1435-1442.

[10] C. Nativi, R. Gualdani, E. Dragoni, L.D.C. Mannelli, S. Sostegni, M. Norcini, G. Gabrielli, G. La Marca, B. Richichi, O. Francesconi, A TRPA1 antagonist reverts oxaliplatin-induced neuropathic pain, Sci. Rep. 3 (2013).

[11] Z. Chen, C.M. Fillmore, P.S. Hammerman, C.F. Kim, K.-K. Wong, Non-small-cell lung cancers: a heterogeneous set of diseases, Nat. Rev. Cancer 14 (8) (2014) 535-546.

[12] S. Bhattacharya, M.A. Socinski, T.F. Burns, KRAS mutant lung cancer: progress thus far on an elusive therapeutic target, Clin. Trans. Med. 4 (1) (2015) 1-11.

[13] F. Amissah, R. Duverna, B.J. Aguilar, R.A. Poku, G.-E. Kiros, N.S. Lamango, Polyisoprenylated methylated protein methyl esterase overexpression and hyperactivity promotes lung cancer progression, Am. J. Cancer. Res. 4 (2) (2014) 116-134

[14] G. Vandal, B. Geiling, D. Dankort, Ras effector mutant expression suggest a negative regulator inhibits lung tumor formation, PLoS One 9 (1) (2014) e84745.

[15] B.E. Johnson, J.V. Heymach, Farnesyl transferase inhibitors for patients with lung cancer, Clin. Cancer Res. 10 (12) (2004) 4254-4257.

[16] J.M. Kraus, C.L. Verlinde, M. Karimi, G.I. Lepesheva, M.H. Gelb, F.S. Buckner, Rational modification of a candidate cancer drug for use against Chagas disease, J. Med. Chem. 52 (6) (2009) 1639-1647.

[17] N.M. Appels, J.H. Beijnen, J.H. Schellens, Development of farnesyl transferase inhibitors: a review, Oncologist 10 (8) (2005) 565-578.

[18] J.M. Kraus, H.B. Tatipaka, S.A. McGuffin, N.K. Chennamaneni, M. Karimi, J. Arif, C.L. Verlinde, F.S. Buckner, M.H. Gelb, Second generation analogues of the cancer drug clinical candidate tipifarnib for anti-chagas disease drug discovery, J. Med. Chem. 53 (10) (2010) 3887-3898.

[19] F.S. Buckner, J.A. Urbina, Recent developments in sterol 14-demethylase inhibitors for Chagas disease, Int. J. Parasitol. Drugs Drug Resist. 2 (2012) 236242.

[20] R.C. Braga, V.M. Alves, A.C. Silva, M.N. Nascimento, F.C. Silva, L.M. Liao, C.H. Andrade, Virtual screening strategies in medicinal chemistry: the state of the art and current challenges, Curr. Top. Med. Chem. 14 (16) (2014) 1899-1912.

[21] C.-K. Chen, P.S. Doyle, L.V. Yermalitskaya, Z.B. Mackey, K.K. Ang, J.H. McKerrow, L.M. Podust, Trypanosoma cruzi CYP51 inhibitor derived from a Mycobacterium tuberculosis screen hit, PLoS Negl. Trop. Dis. 3 (2) (2009) e372.

[22] J.Y. Choi, C.M. Calvet, S.S. Gunatilleke, C. Ruiz, M.D. Cameron, J.H. McKerrow, L. M. Podust, W.R. Roush, Rational development of 4-aminopyridyl-based inhibitors targeting trypanosoma cruzi CYP51 as anti-chagas agents, J. Med. Chem. 56 (19) (2013) 7651-7668.

[23] P.S. Doyle, C.-K. Chen, J.B. Johnston, S.D. Hopkins, S.S. Leung, M.P. Jacobson, J.C. Engel, J.H. McKerrow, L.M. Podust, A nonazole CYP51 inhibitor cures Chagas disease in a mouse model of acute infection, Antimicrob. Agents Chemother. 54 (6) (2010) 2480-2488.

[24] J.Y. Choi, C.M. Calvet, D.F. Vieira, S.S. Gunatilleke, M.D. Cameron, J.H. McKerrow, L.M. Podust, W.R. Roush, R-configuration of 4-aminopyridyl-based inhibitors of CYP51 confers superior efficacy against trypanosoma cruzi, ACS Med. Chem. Lett. 5 (4) (2014) 434-439.

[25] O. Hucke, M.H. Gelb, C.L. Verlinde, F.S. Buckner, The protein farnesyltransferase inhibitor Tipifarnib as a new lead for the development of drugs against Chagas disease, J. Med. Chem. 48 (17) (2005) 5415-5418.

[26] T.-C. Chou, P. Talalay, Quantitative analysis of dose-effect relationships: the combined effects of multiple drugs or enzyme inhibitors, Adv. Enzyme Regul. 22 (1984) 27-55.

[27] Y. Wu, P. Pradhan, J. Havener, G. Boysen, J.A. Swenberg, S.L. Campbell, S.G. Chaney, NMR solution structure of an oxaliplatin 1, 2-d (GG) intrastrand crosslink in a DNA dodecamer duplex, J. Mol. Biol. 341 (5) (2004) 1251-1269.

[28] F. Neese, The ORCA program system, Wiley Interdiscip. Rev. Comput. Mol. Sci. 2 (1) (2012) 73-78.

[29] A.D. Becke, Density-functional thermochemistry. III. The role of exact exchange, J. Chem. Phys. 98 (7) (1993) 5648-5652.

[30] R. Ditchfield, W.J. Hehre, J.A. Pople, Self-consistent molecular-orbital methods, IX. An extended Gaussian-type basis for molecular-orbital studies of organic molecules, J. Chem. Phys. 54 (2) (1971) 724-728.

[31] P.J. Hay, W.R. Wadt, Ab initio effective core potentials for molecular calculations. Potentials for the transition metal atoms Sc to $\mathrm{Hg}$, J. Chem. Phys. 82 (1) (1985) 270-283.

[32] A. Suvitha, N.S. Venkataramanan, H. Mizuseki, Y. Kawazoe, N. Ohuchi, Theoretical insights into the formation, structure, and electronic properties of anticancer oxaliplatin drug and cucurbit [n] urils $n=5$ to 8 , J. Inclusion Phenom. Macrocyclic Chem. 66 (3-4) (2010) 213-218.

[33] A.C. Ashley, D.J. Sargent, S.R. Alberts, A. Grothey, M.E. Campbell, R.F. Morton, C. S. Fuchs, R.K. Ramanathan, S.K. Williamson, B.P. Findlay, Updated efficacy and toxicity analysis of irinotecan and oxaliplatin (IROX), Cancer 110 (3) (2007) 670-677.

[34] A. Falcone, S. Ricci, I. Brunetti, E. Pfanner, G. Allegrini, C. Barbara, L. Crinò, G. Benedetti, W. Evangelista, L. Fanchini, Phase III trial of infusional fluorouracil, leucovorin, oxaliplatin, and irinotecan (FOLFOXIRI) compared with infusional fluorouracil, leucovorin, and irinotecan (FOLFIRI) as first-line treatment for metastatic colorectal cancer: the gruppo oncologico nord ovest, J. Clin. Oncol. 25 (13) (2007) 1670-1676.

[35] A.T. Baines, D. Xu, C.J. Der, Inhibition of Ras for cancer treatment: the search continues, Future Med. Chem. 3 (14) (2011) 1787-1808.

[36] A.A. Adjei, J.N. Davis, L.M. Bruzek, C. Erlichman, S.H. Kaufmann, Synergy of the protein farnesyltransferase inhibitor SCH66336 and cisplatin in human cancer cell lines, Clin. Cancer Res. 7 (5) (2001) 1438-1445.

[37] F. Pampaloni, E.G. Reynaud, E.H. Stelzer, The third dimension bridges the gap between cell culture and live tissue, Nat. Rev. Mol. Cell Biol. 8 (10) (2007) 839845.

[38] K.M. Yamada, E. Cukierman, Modeling tissue morphogenesis and cancer in 3D, Cell 130 (4) (2007) 601-610.

[39] P. Tekchandani, K.B. Das, S.R. Paliwal, Nanomedicine to deal with cancer cell biology in multi-drug resistance, Mini Rev. Med. Chem. (2016) [Epub ahead of print].

[40] C.C. Tièche, R.-W. Peng, P. Dorn, L. Froment, R.A. Schmid, T.M. Marti, Prolonged pemetrexed pretreatment augments persistence of cisplatin-induced DNA damage and eliminates resistant lung cancer stem-like cells associated with EMT, BMC Cancer 16 (1) (2016) 1.

[41] L.S. Mulcahy, M.R. Smith, D.W. STacey, Requirement for ras proto-oncogene function during serum-stimulated growth of NIH 3 T3 cells, Nature 313 (5999) (1985) 241-243.

[42] G. Zhang, Y. An, X. Lu, H. Zhong, Y. Zhu, Y. Wu, F. e. Ma, J. Yang, Y. Liu, Z. Zhou, A novel naphthalimide compound restores p53 function in non-small-cell lung cancer by reorganizing the bak-bcl-xl complex and triggering transcriptional regulation, J. Biol. Chem. M115 (2015) 669978.

[43] A.K. Ferreira, K.F.M. Pasqualoto, F.A. Kruyt, F. Palace-Berl, R.A. Azevedo, K.M. Turra, C.P. Rodrigues, A.C.F. Ferreira, M.A.C. Salomón, P.L. de Sá, BFD-22 a new potential inhibitor of BRAF inhibits the metastasis of B16F10 melanoma cells and simultaneously increased the tumor immunogenicity, Toxicol. Appl. Pharmacol. 295 (2016) 56-67.

[44] P.D. Dans, E.L. Coitino, Density functional theory characterization and descriptive analysis of cisplatin and related compounds, J. Chem. Inf. Model. 49 (6) (2009) 1407-1419.

[45] I.V. Tetko, G.I. Poda, C. Ostermann, R. Mannhold, Accurate in silico log P predictions: one can't embrace the unembraceable, QSAR Comb. Sci. 28 (8) (2009) 845-849.

[46] P. Tyagi, P. Gahlot, R. Kakkar, Structural aspects of the anti-cancer drug oxaliplatin: a combined theoretical and experimental study, Polyhedron 27 (18) (2008) 3567-3574.

[47] H.P. Varbanov, M.A. Jakupec, A. Roller, F. Jensen, M. Galanski, B.K. Keppler Theoretical investigations and density functional theory based quantitative structure-activity relationships model for novel cytotoxic platinum (IV) complexes, J. Med. Chem. 56 (1) (2012) 330-344. 